\title{
Epistemology, Logic and Language (An Analysis of Logic of Language)
}

\author{
Zaimul Am \\ Department of Islamic Education, Faculty of Islamic Studies, University of Muhammadiyah, Tangerang, Indonesia \\ Email address: \\ zaimul.am@uinjkt.ac.id

\section{To cite this article:} \\ Zaimul Am. Epistemology, Logic and Language (An Analysis of Logic of Language).International Journal of Philosophy. \\ Vol. 6, No. 3, 2018, pp. 68-75. doi: 10.11648/j.ijp.20180603.12
}

Received: August 19, 2018; Accepted: September 30, 2018; Published: October 31, 2018

\begin{abstract}
This article attempts to describe and to analyse the philoshopical point of views regarding epistemology, logic and language and the possible relation bertween those three branches of philolosophical inquiries. The method used in this research is analytical method because many arguments of philosophers has to be analysed in order to portray the whole picture of the correlation between epistemology, logic and language. This article shows that there is a close connection between the study of knowledge and the study of language as a medium to express what is known. Philosophers are generally interested in discussing the relationship between mind, word and reality. Some of them have come to a conclusion that the words are at a crossroads: do they want to reflect what is in the mind or to reflect what is in reality. Then how to distinguish between the correct sentences (propositions) from the wrong ones. Grammatical analysis stops only at the limitofthe relationship between sentences and grammatical rules as a truth test of a proposition. But how to test the truth of the content (property, essence, substance) of a proposition? Many philosophical theories are put forward but still that such things as mind are a mystery, words and sentences also form their own mysteries.
\end{abstract}

Keywords: Epistemology, Logic, Language

\section{Introduction}

The word logic of language is often interpreted as a way to distinguish between meaningfulness and nonsense in language. Wittgenstein, for example, states that the logic of language becomes a way to make an objective distinction in the context of philosophy by extending the concept of grammar to include every description about the use of language. In this way, Wittgenstein aligns logic with language because logic explains the rules of meaning and nonsense (or the meaning of language) and not just the form. He believes that without realizing it, language disguises the structure of thought. It was the task of philosophy, he said, to reveal the original form of thought behind the curtain of ordinary language. Complex propositions must be reduced to simple propositions and simple propositions must be expressed as images of reality. [1]

Bertrand Russell acknowledged problems in language. First, there is a problem about what is actually in our minds when we use language with the intention of interpreting something with it. This problem is related to psychology.
Second, there is aproblem that relates to what relationships exist between thoughts, words or sentences and to what they refer to or can be interpreted. This problem is part of epistemology. Third, there are problems in the use of sentences, for example to convey the truth and not mistakes. This issue is part of a special science that discusses sentences. Fourth, there is a question: what relationship must a fact has (eg a sentence) with other facts so that it can become a symbol for others? This is a problem of logic. [2]

In this case, the researcher intends to carry out an investigative study of epistemology and language on the one hand, and the relationship between the two which forms the logic of language, on the other. The word philosophy of language is also often used to show the relationship between epistemology and language. In other words, whether the mind becomes the principle of arrangement for language and not reversely. Language influences laws in mind. Immanuel Kant once drew a parallel line between mind and language by making an analogy between logic and grammar. Kant states that logic deals with the overall use of understanding as grammar relates to a language. [3] 
Epistemology is often defined as the study of the basics, nature, sources of knowledge and limits of human understanding. Epistemology also addresses issues such as how knowledge is acquired and how knowledge is tested and then considered as correct. There is an analysis which states that useful discussion about it should be started by understanding some basic language facts relating to how the verb to know and its parts function within the usual range of the relevant discussion. The first step is understanding that to know has both propositional and procedural meanings: there is an intellectual problem about knowing that something and another is a case (that-knowledge) and a practical matter about how to do an action in order to achieve a goal (how-toknoowledge). This difference is very important because it is only the first, namely the form of intellectual and propositional knowledge, which in general has become the focus of attention in traditional epistemology, and not the second, namely the form of practical knowledge. [4]

The philosophy of language examines natural language, such as English and engineered languages, such as logic and mathematics. The word language can mean personal use in the mind and its use in public to communicate the mind. The central fact of language is its representational nature. Philosophy of language also studied the relationship between meaning and truth. For S to be meaningful, it must be able to reflect the world as it is in various ways because that is the way $\mathrm{S}$ reflects the world. Because of the $\mathrm{S}$ truth conditions, $\mathrm{S}$ becomes meaningful if it fulfills the conditions of truth. Thus, systematic assessment of meaning requires a framework for determining the requirements of sentence's truth based on their syntactic structure, and representational contents of their parts. [5]

But there are several issues regarding this. First, what really must be represented by language: the mind or the world outside one's self (facts)? Second, the mind contains things that are abstract and universal while reality is concrete and particular. In this context, can language be a meeting point for the two very different realms? Third, there is a very serious question: how do we test the truth of knowledge? If our mind cannot grasp reality in its entirety and so does the senses, the meaning of truth as what is compatible with reality will become useless.

This research attempts to unravel the inside-outside of tripartite relationship between mind, language and reality. Knowledge of the characteristics of the mind is expected help to reveal the obvious problem of the mystery of using the words when they are placed both as a mirror of the mind or as a picture of reality as initiated by Wittgenstein.

\section{Research Methodology}

This research uses a manuscript study (content analysis) as long as it relates to the study of thoughts of philosophers who discuss about the epistemology, language and logic of language both from primary sources and secondary ones. The researcher also uses descriptive-analytical methods because this research is an analytical and critical exposure to various philosophers' thoughts about epistemology, language and logic of language.

This study also used comparative methods especially with the aim to draw similarities and differences between the philosophers' thoughts. Whereas the text research method used is interpretive method, which is a method that provides broad freedom for researcher in interpreting the text and because this method matches overall study approach that is analytical.

The approach used in this study is a philosophical approach. This is because the discussion of epistemology, language and logic of language requires a radical approach to understanding each conceptual nature and the way the three aspects of human life relate to each other.

\section{Thoughts and Characteristics of the Objects of Reason}

The fundamental question related to reason and the characteristics of the object of reason can be "What is the object of reason?" The proposition "I am thinking about unicorn," clearly shows that there is a certain object being thought of. The theory of existing objects (subsistent objects) provides an alternative answer and seems to be based on the consideration that we are thinking about something when we think about unicorn. But G.E. Moore rejected this idea. According to him, the theory of subsistent objects has failed to distinguish between the logical and grammatical forms of statements such as "I was thinking about unicorn" and "I was hunting lion." The first proposition contained objects of thought that were not in reality (unicorn) while the second contains "something" (lion) in reality. [6]

In an epistemological context, reason is seen as the power of the mind by which sensory weakness is overcome. With the mind, knowledge of everything that is outside of ourselves, for example knowledge of beings, facts and events, is obtained by "transcending" the sensory range. The mind ensures for us not only things those are natural, immaterial, now, yesterday or later; but even though the mind is powerless, it is infinite within its reach. It can reach the end of the universe even to the Throne of God. The mind gives us knowledge, whether real or uncertain, still knowledge, at any level in terms of perfection and from any side. Newman identifies two functions of reason when we think, namely drawing conclusions (inferences) from various premises, and justifying a conclusion. Keep in mind that both are very different from each other. We often justify a proposition when we forget about the reason for that justification; on the contrary, justification may also be given without reason or based on wrong reasons. Reason can be a better or worse reason, but justification can or cannot. It is true that arguments may be very interesting so that justification immediately follows the conclusion. [7]

Locke argues that no truth can be demonstrated in concrete matters and therefore, justification for a concrete proposition must be conditional and far from certainty. Absolute 
justification does not have a legitimate function except the act of "ratifying" intuition or demonstration. [7]

Muslim philosophers also discuss much about the function of reason and various forms of knowledge derived from it. Al-Kindi mentions that reason performs when genera and species are united by the soul, so they become intelligibles. The soul really becomes rational after its union with the species. After this union, potentially, the soul becomes rational. However, everything that is in potentiality does not come into actuality except by something that does indeed function to bring it from potentiality to actuality. It is the genera and species of all things, namely things that are universal, which carry a soul that is potentially rational to actually becomes rational. [8]

According to al-Farabi, logic is the science that provides rules that can correct the mind, direct people to the path of truth and bring them far away from error. Al-Farabi views logic as having the same position on intelligible objects as well as grammar towards words and prosodies on verses in poetry. He emphasizes practical aspects and applied logic that shows that objects of reason must be tested by their rules as well as dimensions, content and weight by their measurements. But al-Farabi always pays attention to the difference between grammar and logic. The first only relates to words while the second discusses the meaning associated with words while the meaning does have something to do with words. In addition, grammar examines different language rules between different communities and races. Whereas the logic discusses human reason that is always the same everywhere. [9]

Al-Farabi divides reason into two parts. First, practical reason (al-'aql bi al-fi'l) which draws conclusions about what must be done and theoretical reason which helps the soul to reach its perfection. Material reasoning is divided into three parts, namely material reason, habitual reason and acquired reason ( 'aql al-mustafâd).

Material reason, or sometimes called by al-Farabi as a potential sense, is the soul or part of the soul that has the power to abstract and to understand the material nature of everything. It can almost be equated with something material that in which the form of everything is paired, just like a candle that becomes one with the inscribed letter to it. The writing is nothing except the senses and the objects of reason. Thus, the objects of reason are potentially sensible. When they are abstracted from the senses, they are actually in the reason. That explains perception and abstraction, the essential performance of the reason which converts all of its objects from potentiality to actuality. When these various objects of thought are conveyed to the mind, reason is then changed from intellect in potential to become intellect in action. [10]

Therefore, actual intellect-or sometimes referred to as habitual intellect - is one of the levels of reason in obtaining a number of its objects. Even though the reason is unable to understand all of its objects, it is actual intellect that relates to what it perceives and potential sense relates to what it has not perceived. The objects of reason themselves are potentially inside sensed objects. When an object of reason is removed from a sensed object, it becomes an actual object of reason. Then when someone has reached this level of actual reason, he can know himself. This type of understanding has nothing to do with the world outside because it is an abstract mental understanding. [10]

The difference between rational conception and sense perception is that the first is a form of intuition or in other words, it is a kind of direct understanding (immediate apprehension). This is the highest level of human understanding and can only be achieved by someone who reaches the level of 'aql mustafâd (acquired intellect) where the hidden becomes revealed and he arrives at a direct connection with the realm of the angels. [11]

Thus, reason is able to slowly rise from potential to actual and ultimately becomes'aql al-mustafâd. The intertwined two levels are different from each other even though the lower always function as step for the other. Although potential reason functions only as the recipient of sensory object forms, actual reason maintains objects of reason and understands concepts. 'Aql al-mustafâd rises to the level of communion, ecstasy and inspiration. Conception is a different level; in the beginning it is an object of reason that potentially exists inside the material; when the object of reason at this stage is abstracted from matter, it becomes an actual object of thought. What remains higher is the abstract forms that have never been in the material. [11]

To understand the reason and the characteristics of the object of reason accurately, it is important to put forward two important elements that are closely related to the object of reason, namely matter and form. According to Aristotle, the form of something is the total number of essential and universalizable properties that make up its definition. The material on everything is matter which has the potential to accept these qualities - forms - and with which forms become an individual existence. But there are two kinds of great difficulties in this conception in terms of the actual existence of something. The first is that forms are universal and therefore they do not exist. The material also-because it becomes pure potentiality - does not exist because it is only actualized by form. Then how can something come into being by an existence that is not existent and by a material that has no existence? The second arises from the fact that although in general Aristotle argues that the definition or essence of something is its form but he says in some important parts of his work that matter is also contained in the essence of something, because if not so, of course, we would only have a partial definition from him. Then if we view matter and form as forming definitions, we will never arrive at an actual existence of something.

This is why Ibn Sina to argue that from form and matter alone we will never obtain a concrete existence except only limited characteristics of essences and accidents. Ibn Sina has at length analyzed the relationship between form and matter. He concluded that matter as well as form depended on God and that arranged entities could not be caused by form and matter alone, but also by "something else." Finally Ibn Sina 
concluded that everything other than God needs existence from the others. [12]

Efforts to uncover the relationship between mind and object are also carried out by Hegel. Hegel's dialectical theory reflects an understanding of fundamental truthsincluding psychological truth-about reality, the way it is perceived and how the soul is created and reaches its full actualization through the interaction of self-consciousness and awareness of something else (consciousness of an other). The Hegelian system is basically related to the soul as a product of dialectical interaction between subjective thoughts and objective nature, between logic and the universe. Everything starts with logic, Hegel said, defined as the idea (the Idea in itself) which addresses the human reason and the inner life of the reason. It is then accompanied by Natural Philosophy, which is the science of ideas outside of itself or for itself which addresses the physical realm. [13]

Wittgenstein gives a clearer picture of reason and the objects of reason. He states that an idea can be expressed in such a way that the elements of propositional sign relate to the objects of reason. What is meant by Wittgenstein with the objects of reason are physical elements whose relationships with each other form thoughts. [14]

The discourse on the reason and the characteristics of the objects of reason can be considered as a continuation of the ancient debate between Plato and Aristotle regarding form and matter and their relationship to the realm of ideas and physical nature. The ancient Greek philosophers generally always tried to alleviate the paradox inherent in permanence and change as the characteristic of reality. If an object is permanently real, how can it be something different? If the natural law determines that ultimate reality is eternal and unchanging, how can we explain the phenomenon of movement and change?

Plato seeks to overcome the above problem by initiating dualism in which eternal ideas become guiding principles and have various inherent patterns related to everything we perceive with senses. Everything in nature (phenomenon) develops from one level to another at all times because it wants to imitate or correspond to eternal ideas. [15]

Aristotle rejected sharp separation between two different natures - namely the nature of ideas and the nature of objects perceived by everyone. He prefers empirical notion that ideas postulated by Plato actually form the essence of objects from sensory perception. Plato's Ideal Reality reveals himself in the natural phenomenon around us that we know through sensory experience. For Plato, the sensory realm manifests itself by imitating the realm of ideas. As for Aristotle, the Platonic Realm of Idea manifests itself through the realm of phenomenon. According to Aristotle, Plato's concept of the universals will always be found in particular things (objects of experience). Ontologically, Plato's concept of real objects (ideas) is given an essential term by Aristotle. In other times, he also calls it forms, that are intelligible essences. According to Plato, essence (Ideas) is truly independent of everything that is particular. For Aristotle, essence will only become real if it is actualized, i.e when it manifests itself in the realm of phenomenon then it takes on a form that can be captured by the senses. [15]

From what is described above, it can be stated that reason is the power of the soul that has the ability to think. There are two broad categories of the objects of reason, namely: First, the reason itself when viewed in terms of its norms and laws. Second, reality is full of changes that are in the material world (material world) or the world of phenomenon.

\section{The Function of Language: A Philosophical Review}

Just as there is a mystery in the relationship between matter and form, so there is a mystery in the relationship between thought and concept on the one hand, and language on the other.

In this context it is certainly worth to discuss the basic functions of language (propositions). In fact, there is a theory that states that the essence of a proposition is to represent or to reflect something. Propositions reflect the world in any way. If propositions do not reflect the world, it is difficult to view them as the highest bearers of truth values. Propositions can also be seen as the objects of reason in the modern sense. [16] It can also be said that what the language wants to communicate is the mind. If the extraction of the language is done, the word that will appear is the word as a sentenceforming component.

In other term, words give an understanding of the components of what the language wants to communicate. The underlying idea is that if words become the basic component of language so the meaning of words must be the basic component of what is meant by language. It is possible that people think that the meaning (whatever it is) of words which a component of language is the same as the meaning (whatever it is) of the words which becomes the components of the sentence. Sentences are formed by words and however they are spoken or written, they are still arranged in sentences. But why should we think that words are the basic component of sentences? What about letters (if sentences are written) or sounds (if sentences are spoken)? The answer is that words are considered as a basic component of sentences as long as they are related to the meaning. The meaning of sentence systematically depends on the meaning of words those make it up. But the meaning of words does not systematically depend on the meaning of parts of words. [17]

In the relation of word with the meaning, there are several philosophical theories. One of them is referential theory. The grand idea of this theory is that linguistic expressions have meaning because they represent or reflect something. The meaning of an expression lies in what it represents. In this theory words become labels. Words are symbols that reflect, express, name, interpret or refer to entities in the world: the name Adolf Hitler means (person) Hitler, the noun "tiger" refers to the tiger, and so on. The phrase "cat sits on a mat" reflects the sitting of a cat on a mat. Thus, the sentence reflects the properties of something that is mentioned and 
that is how the sentence is used to express something. [18]

The referential theory of linguistic meaning will explain the meaning of all expressions according to their conventional connection with everything or with certain traits in the world, and it will explain how humans understand a sentence that someone knows what is mentioned by words as a component of sentences. Referential theory seems strong enough. But there are some objections to it. First, not all words refer to the actual object. For example, the word Pegasus has no meaning because there is no reality of winged horses that can be referred to as the meaning of those words. Second, the word fat on a simple sentence that contains a subject and predicate, for example the sentence "Socrate is fat." It can be said that the word fat refers to something abstract. For example, it and various other adjectives might be considered to refer to the qualities of everything. The word fat may be used to name obesity in abstractions, or as mentioned by Plato, "the essential fat in the Realm of Ideas." Third, there are words which are grammatically considered as nouns when they are not and intuitively name a few things which is not something absent or abstract characteristics. For example, the words "by", "by name" and "blessing." It is often said that a person can achieve something thanks to his hard work. But "blessing" is not something or one type of thing. In addition to its position as a noun, such words have no meaning obtained by referring to certain types of objects. [18]

The meaning of a word can also relate to three important aspects in the philosophy of language, namely the relationship of meaning and purpose, the relationship of meaning with truth and the relationship of meaning with metaphysics.

In the first part of the study, namely the relationship between meaning and purpose, there is a distinction between the meaning of the sentence and the purpose of the person speaking. The meaning of sentences relates to the direct and literal meaning of a particular type of sentence. Here is an example of a statement about the meaning of the sentence from "Jones is an efficient administrator."

1) Jones is an efficient administrator which means that Jones is an efficient administrator.

2) In Frege's scheme, the phrase "Jones is an efficient administrator" will be the correct sentence if, and only if, Jones is truly an efficient administrator. [19]

As long as it relates to the relationship between the meaning of the sentence and the intention of the speaker, there is a question, "Do we explain the meaning of the sentence according to intention of the speaker, or vice versa?" In Fregs's scheme, the questions about the meaning of the sentences discussed by semantics, and the questions about the intention of the speaker explained by pragmatics. The main problem that must be discussed by pragmatics is "in view of a sentence type has a meaning of a particular sentence, so what determines intention of the speaker to say such a sentence?"In the Frege's scheme, an explanation of the meaning of the sentence-according to the conditions of truth-appears first while the explanation of the intention of the speaker comes later. [19]

In the relationship between meaning and truth, several theories emerge. Davidson explained that when he talked about a theory of meaning, he immediately remembered Frege's concept of meaning. Frege argues that an adequate view of language will encourage us to arrive at three sentence's characters: reference (semantic value), meaning and power. Davidson also stated that a theory of truth originates from a type of truth's definition. Tarsky tells us everything we need about meaning. By calculating the truth in the reference domain (semantic values) as Frege did, a study of the meaning will submit to the study of references (semantic values). [19]

In this context too, there are several theories of truth in philosophy. All of these theories are closely related to the content of a sentence with the words and meanings of those words become the main components. It is often said that there are 5 (five) main theories about truth: correspondence theory, coherence theory, pragmatic theory, redundancy theory and semantic theory. Although it is not very clear whether these five theories address the same issue or not, but it is clear that these five theories examine truth and error as content of what people think or say. Some people will explain the truth based on sentences, parts of language, as spoken by certain people at certain times. For them, the sentence becomes the bearer of truth. Some of them even stated that the statements and propositions were the bearers of the truth. But in general, various theories about truth actually discuss the relationship between the world and what we say or think about it. [20]

Correspondence theory states that truth is the relationship between propositions (sentences or beliefs) on the one hand, and the world on the other. The condition of the truth of a proposition, according to this theory, is if it relates or corresponds to the world. Frege rejected the correspondence theory with the following arguments:

1) Assume that truth is a relation of correspondence with the world, then:

2) To find out if "p" is true, we must find out whether "p" relates or corresponds to the world is true.

3) To find out whether "p" relates or corresponds to the world is true, we must find out whether " $p$ " relates or corresponds to the world is true "is true and so on without end.

4) So if we assume that truth is a relation of correspondence with the world, we will never find out whether a proposition is true.

Coherence theory equates the truth of a decision with its coherence to various other beliefs. Various versions of the theory provide different views on coherence. But in all its forms, the point is to say that truth is an internal relationship between various beliefs. This theory states that the truth or mistake of a belief can be determined by finding whether it passed the coherence test or did not. [20]

Pragmatic theory states that the whole meaning of a conception expresses itself in its practical consequences either through the recommended form of action or through 
the expected form of experience, if that conception is indeed true. [21] The pragmatic theory of truth is closely related to Kantian type of coherence theory. He stated that the truth of a belief is a matter of whether it "works" namely whether that belief can have practical effects. Thus, pragmatic theory also makes truth as a matter of coherence, but coherence with future experience. [20]

According to the theory of redundant truth, stating that a statement is true is actually the same as expressing the statement itself. For example, stating the phrase "snow is white is true" is the same as saying the phrase "snow is white." Proponents of this theory draw conclusions from the premise that truth is a recurring concept. In other words, "truth" is only a word commonly used in the context of a particular conversation and not a word that leads to anything in reality. Frank P. Ramsey stated that the use of words like facts and truth as only a rotating way to express a proposition and then treat these words as separate problems that have nothing to do with decision is clearly a "linguistic disorder." Bob Hale and Crispin Wright stated that the theory of redundancy of truth is not a theory of the content of truth, but merely a theory of what the words "are true." This theory holds that "... is true" can be eliminated without the slightest adverse effect on a proposition [20]

The theory of semantic truth states that truth is a content of sentences. This theory distinguishes language that speaks of something (the object of language) and the language that a person uses to talk about something (meta-language). Tarsky spread the understanding of the meaning disguised by the translation in his analysis of the truth. The requirement that "p" translate "s" is part of what guarantees material equality from the definition of truth. The way it works is as follows. Suppose that "s" is true. Because " $p$ " is a translation of "s", of course it must have the same value as "s". That is, it must be right too. Because (T) is true, ("s" is T) and "p" must have the same truth value. Then, ("s" is $\mathrm{T}$ ) is also true. T becomes valid for "s". on the contrary, if "s" is wrong, "p" is also wrong. If "p" is wrong, ("s" is T) is also wrong and T does not apply to "s". Thus, $\mathrm{T}$ applies to all on condition that the sentence $\mathrm{L}$ is true. [20]

Tarsky defines truth based on satisfaction. Satisfaction is a binding relationship between expressions and objects or sequence of objects. In general, it is a discussion of "the right." For example, an object satisfying a predicate "is white" if the predicate "is white" is true of that object."[20]

In the relationship between meaning with the world and metaphysics, there is realism namely the school of philosophy which states that to think that our thinking about something aims to reflect an objective reality and sometimes there is success in achieving this goal. [20]

In addition, there is the most fundamental relationship that needs to be studied, namely the relationship between words (language) and mind. In saying words, a person can express a thought, as well as hearing or understanding someone's words. But there are several problems in this theory. For example, what is that thought? And how does a sentence, which is only a series of sounds/illumination/sign/pattern can express a thought? The second theory attempts to focus on the relationship between words and everything. Many people do not understand the theory of meaning. But many of them know that a noun is certainly a mirror of - or refers to-a certain thing and the view that this relationship is very important to interpret words. [22]

On the other hand, the meaning of a word represents a very intense combination between mind and language, so that is very difficult to say whether a word is a phenomenon of speech or a phenomenon of mind. A word that has no meaning will become a hollow voice: thus, meaning becomes a criterion for the word. The meaning becomes the main component of word. Then there is the impression that meaning can be considered as a phenomenon of speech. But from a psychological point of view, the meaning of each word is a generalization or a concept. And then, because the generalization or concept is clearly an act of the mind, so the meaning can be seen as a phenomenon of thinking. The meaning of a word becomes a phenomenon of the mind only to the extent that the mind becomes part of speech. And speech can be considered as a speech only if it is related to the mind and influenced by the mind. Meaning is a phenomenon of verbal or meaningful speech - an union of words and thoughts. [23]

\section{Logic of Language: Meaning and Scope}

There are various theories which discussabout the relationship between logic and language. These theories in turn form a set of principles that reflect the influence of the mind on the use of language.that is the use of sentences or words.

The relationship between logic and meaning often changes over time and from time to time. In these conditions, people can have confidence about the reciprocal relationship between the way of thinking and the dynamics of change in society and its influence on the use of words. Then there is a phenomenon that makes people think that the true or the right turns out to vary from time to time and from one region to another. Then they start to believe that truth is a conventional problem. They are convinced of this because they believe that truth is shaped by words and the meaning of words changes from time to time and from place to place. It is also a conventional problem that depends on our collective choices.

The interaction between logic and language in general can be divided into three phases. The first phase (early 20th to 1960s) was marked by so many works in the field of logical grammar with the emergence of categorical grammar in the Polish School in the early 20th century and its extensive application of natural language by Yehoshua Bar- Hillel in the early 1950s. In addition, Tarsky's work on conditional semantic truth provides the necessary background for the theoretical-analysis model of natural language and for Montague's grammar in the 1970s. The second phase begins with a crisis of various semantic models that have been 
developed at the beginning of the period of generative grammar and the ups and downs of Generative Semantics. At this time, there was a great debate about the semantics of grammar theory and the first attempt to create extensive comparisons and integration between generative linguistics and logical grammar. The third phase is illustrated very clearly by referring to the main role of Chomsky's theory through the concept of the Form of Logic. [24]

20th century Western philosophers studied the relationship between thought (logic) and language (words, sentences or propositions). Frege, for example, states that the most important concept of logic is truth. It is an analysis of this which encourages him to create a theoretical framework which divided sentences into sections and each section associated with entities that exist in nature in a systematic way. By making truth as the main focus of his thinking, Frege became a pioneer in the study of a semantic concept which later dominated the study of language's logic to this day. Frege saw how an analysis of truth would encourage one to express the meaning of the relationship between expressions of sentences and various extra-linguistic entities. Frege's view of logical analysis of language has marked a complete break with tradition. Frege stated that every categorical proposition has a subject, a predicate, a copula, a quality and a quantity. For example, in the sentence "the righteous are happy," "righteous" and "happy" are terms in which "righteous people" is subject, and "happy" is predicate and "that or is" is a copula. "Quality" propositions are affirmations or negations, while the quantity of a proposition is its universality or particularity. Frege openly rejected the separation between subject and predicate. According to him, the separation between subject and predicate does not have a place in the system about a decision. In this case, Frege claimed to follow the formulation of a mathematical language where subjects and predicates could only be separated by damaging them. [24]

But on the contrary, Frege put forward the separation between objects and functions. According to this concept, the phrase "John is a tall person" must be analyzed into a concept of the word "high" and the name of the person "John." The latter shows an object, which carries the name of a person. Whereas the first shows a concept, which is a function. For Frege, it is an unsaturated entity whose argument is an object and whose value is the truth's value of "True" or "False." Thus, the word concept of "high" shows the concept that every object when the argument conveys the truth value-will be True if and only if the individual indicated by John's word is high. Thus, the entire sentence shows the truth if and only if the individual indicated by John's word is high. Rejection of the separation of subject and predicate becomes increasingly clear in the case of the relational expression. The statement "3 is greater than 2" ("3>2") is not to be analyzed into the subject " 3 " and the predicate "is greater than 2 " but into the relation's symbol analysis "is greater than" and the number name "2 and 3". [25]

It is worth to emphasize that Frege's view of logic and his conceptual notes has opened the door to various possibilities that has never been imagined by his predecessors. There are several things can be stated. First, in Frege's thinking there is, for the first time, the idea about derivational history of a sentence with the produced possibility to determine the truth or error in several stages, beginning with the atomic stage. Frege's procedure is not always closely related to the truththat is the truth of a arranged sentence cannot be obtained in the correctness of the arrangement and this is due to the simple thing: the arrangement is not always a sentence. Therefore, the phrase "everyone is mortal" is true if, and only if, "Ahmad dies", "Budi dies" and so on, that is, if and only if the first level concept of word "dies", contains the value of the Truth when we apply to all (names) objects in the universe of of persons. Second, Frege's categorical distinction between objects and concepts, and the syntactic distinction between intact expressions and incomplete ones which then gives rise to a hierarchy of levels and which, in turn, conveys a theory of significance for sentences in natural language. In other words, he was able to explain why certain sentences in natural language, though grammatical, became meaningless and paradoxical. [25]

Edmund Husserl paid special attention to the issue of what makes expression in natural language being meaningful. The Husserl's answer to this question was the same as Frege's. That is, as long as the phrase complies with the principles of combination and substitution those govern the categories of its origin. Thus, like Frege, Husserl makes categorical distinctions and openly states the relationship between various expressions those come from various categories. The relationships are codified in what is referred to as the rules of meaning's relationship which state the forms (modes) and substitutions of various expressions into a more complicated relationship. These rules allow Husserl to explain why certain links in language are nonsensical. Logical grammar is the same set of a priori rules for all languages. To understand Husserl's version of the meaning's relationship, we must first understand Husserl's distinction between form and matter, that is, between expressions that show forms and expressions which show matter. In the example sentence: This house is green.

The word (this) and (is) do not have an independent meaning: they are syncategorematic expressions, that is, expressions that can be meaningful only after being combined with other expressions. For Husserl, the syncategorematical expression shows form, which is inversely proportional to nominal expressions, such as houses and the expression of adjectives such as the word "green", which shows matter, namely everything and entities in the world and so on. [25]

Al-Farabi has outlined various components of the sentence. He divides the word (al-lafzh) in its relation to meaning into three parts: single word that has single meaning, structured word that has single meaning and structured word that has structured meaning. Words which show single meaning are divided into three parts: names, words and auxiliaries (copula). Names are words which indicate single meaning and they can be understood independently, without having to show their position in a 
sentence or by quality, and the meaning is related to a certain time. A word is a single word that shows meaning, can be understood independently and the meaning can also be indicated by its position in a sentence but not by quality. The meaning of the word is valid for a certain time. Time is limited in three senses: past, now and future. While the auxiliaries (adâh, copula) are words that show a single meaning. They cannot be understood meaning unless they are combined with other words. Examples of auxiliaries are "from", "above" and so on.[26]

Al-Farabi also discussed various possibilities relating to the meaning of the sentence. According to al-Farabi, sentences are arranged words and they show a set of meanings. Each part shows by its essence-not by its quality - part of that meaning. Some argue that in it is a part that shows the meaning of that part so there is a separation between the part and the arranged word that shows a single meaning. For example, the word "Abd al-Malik" shows someone's nickname. In fact the part of the word does not show the part of that person.

Al-Farabi mentions that linguistics is divided into seven broad categories. Namely, the knowledge of single words (vocabulary), the knowledge of arrangedwords, the knowledge of the rules of words in their position as single words or arranged words, the rules of writing, the rules of reading, and the rules of poetry. Each of these sciences explains the function of words in spoken and written sentences. [9]

\section{Conclusion}

From what was described above, it can be concluded that language which includes sentences or words can reflect the mind and can also reflect reality. Philosophers who think that the word reflects the mind tends to view sentences or words as a manifestation of the mind that does not always have to relate to reality. While philosophers who think that words must reflect reality regard the word as a picture of reality. All ofthem has to deal with two problems. First, the existence of assistive words such as from, above and so on that do not have reality. Second, the parts of the sentence that are considered as images of reality which are not necessarily parts of reality itself.

\section{References}

[1] Proops, Ian, Logic and Language in Wittgenstein's Tractatus, New York: Garland Publishing, 2000, 61.

[2] Russel, Bertrand, "Introduction" in Ludwig Wittgenstein, TractatusLogico-Philosophicus, New York: Routledge, 1974, $\mathrm{x}$.

[3] Forster, Michael N., Kant's Philosophy of Language, Germany: tijdschriftvoorfilosofie, 2009, 488.

[4] Rescher, Nicholas, Epistemology, An Introduction to the Philosophy of Knowledge, New York: State University of New York Press, 2003, xiii-xiv.
[5] Soams, Scott, Philosophy of Language, Princeton: Princeton University Press, 2010, 1.

[6] Melden, A.I., "Thought and It's Objects" in Roland Houde and Joseph P. Mullally, Philosophy of Knowledge, New York: J.B. Lippincott Co., 1960, 115.

[7] Kenny, Anthony, A New History of Western Philosophy, Oxford: Oxford University Press, 2004, 147.

[8] El-Ehwany, Ahmad Fouad, Al-Kindi,Sharif, MM.,History of Muslim Philosophy, Wiesbaden: Otto Harrasaoit, 1963, 433.

[9] Al-Farabi, Ihshâ al-'Ulûm, Beirut: Dar waMaktabah al-Hilal, 1996, 53-62, 25.

[10] Al-Farabi, al-Tsamrah al-Mardhiyyah, Beirut: Dar al-Farabi, 1982, 49-54.

[11] Al-Farabi, Arâ' Ahl al-Madînah al-Fâdhilah, Beirut: Dar alMasyriq, 1986, 46-52.

[12] FazlurRahman, IbnSina, in MM. Sharif, History of Muslim Philosophy, 433.

[13] Hester Solomon, "The Trancendent, Function and Hegel's Dialectical Vision", in Journal of Analytical Psychology, vol. 39, London: Blackwell Publishing Ltd., 1994, 78.

[14] Philosophy in the Modern World, Oxford: Clarendon Press, 2007, 208.

[15] Sahakian, William S., History of Philosophy, New York: Barnes and Noble Books, n.d, 66-67.

[16] Jubien, Michael, "Propositions and the Objects of Thought" in Philosophical Studies 104 Netherlands: Kluwer Academic Publisher, 2001, 47.

[17] Morris, Michael, An Introduction to the Philosophy of Language, Cambridge: Cambridge University Press, n.d., 15.

[18] Lycan, William G., Philosophy of Language, New York: Routledge, 2001, 5-6.

[19] Miller, Alexander, Philosophy of Language, New York: Routledge, 2007, 247-272.

[20] Hale, Bob and Crispin Wright, A Companion to the Philosophy of Language, Oxford: Blackwell Publisher, 1998, 307-326.

[21] Rydenfelt, Henrik, "Meaning and Pragmatism. James on the Pragmatic Consequence of Belief" Helsinki: University of Helsinki, 2008, 4.

[22] Lee, Barry (ed), Philosophy of Language: The Key Thinkers, (London: Continuum, n.d., 6.

[23] Vygotsky, Lev, Thought and Language. London: The MIT Press, 1986, 212.

[24] Lenci, Alessandro and Gabriel Sandu, Logic and Linguistic in the Twentieth Century, Helsinki: University of Helsinki, n.d. 3-4.

[25] Frege, G. (), "Function and Concept", in Brian McGuiness (ed.) GottlobFrege: Collected Papers on Mathematics, Logic, and Philosophy, Basil: Basil Blackwell, 1984, 139, 6-9.

[26] Al-Farabi, Kitâb fi al-Manthiq, Kairo: al-Hay'ah alMishriyyah al-'Ammahlil-Kutub, 1976, 7-16. 